\title{
Life Cycle Assessment of electricity production in Italy from anaerobic co-digestion of pig slurry and energy crops
}

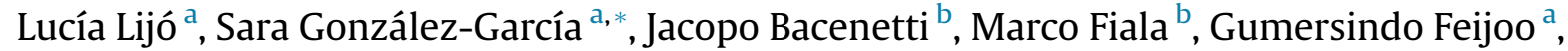 \\ Juan M. Lema ${ }^{a}$, María Teresa Moreira ${ }^{a}$ \\ ${ }^{a}$ Department of Chemical Engineering, Institute of Technology, University of Santiago de Compostela, 15782 Santiago de Compostela, Spain \\ ${ }^{\mathrm{b}}$ Department of Agricultural and Environmental Sciences, Università degli Studi di Milano, via Celoria 2, 20133 Milano, Italy
}

\section{A R T I C L E I N F O}

\section{Article history:}

Received 15 July 2013

Accepted 3 March 2014

Available online

\section{Keywords:}

Anaerobic co-digestion

Bioenergy

Environmental impact

Maize silage

Organic waste

Triticale silage

\begin{abstract}
A B S T R A C T
This study aims to evaluate the environmental consequences and energy requirements of a biogas production system and its further conversion into bioenergy by means of the Life Cycle Assessment (LCA) methodology. To do so, an Italian biogas plant operating with pig slurry and two energy crops (maize and triticale silages) as feedstock was assessed in detail in order to identify the environmental hotspots. The environmental profile was estimated through six impact categories: abiotic depletion potential (ADP), acidification potential (AP), eutrophication potential (EP), global warming potential (GWP), ozone layer depletion potential (ODP) and photochemical oxidation potential (POFP). An energy analysis related to the cumulative non-renewable fossil and nuclear energy demand (CED) was also performed, considering this indicator as an additional impact category.

According to the results, the biomass production subsystem was identified as the main environmental key issue in terms of ADP, AP, EP, ODP and CED, with contributions ranging from $26 \%$ to $61 \%$ of the total impact. Regarding ADP, ODP and CED, these results are mainly related with diesel requirements in agricultural machinery, derived combustion emissions and mineral fertilizers production. Concerning AP and EP the production field emissions derived from fertilizers application was observed as the main contributor. Concerning GWP, this step presents an environmental credit due to the uptake of $\mathrm{CO}_{2}$ during crop growth, which contributes to offset the GHG emissions. The bioenergy production plant significantly contributes to the environmental impact in categories such as GWP (43\%) and POFP (59\%), mostly related with emissions produced in the gas engine and biogas losses. Emissions derived from digestate storage contribute to AP (52\%) and EP (41\%). The use of the digestate as an organic fertilizer has a beneficial role because this action avoids the production and use of mineral fertilizers.

A sensitivity analysis was also conducted to assess the influence of variations in important parameters of biogas systems. The environmental profile of the biogas system turned out to be highly dependent on the selection of system boundaries and the allocation method.

To sum up, this study aims to assess the environmental performance of a biogas technology available not only in Italy but also in other European countries. The environmental analysis of the process under study highlights the environmental benefits of the co-digestion processes, which not only produces biofuel but also reduces the disposal of solid wastes and produces digestate, with special value in the fertilization of agricultural soil.
\end{abstract}

(c) 2014 Elsevier Ltd. All rights reserved.

\section{Introduction}

Nowadays, general scientific consensus believes that global warming is caused by the emission of anthropogenic greenhouse

\footnotetext{
* Corresponding author. Tel.: +34 881816739.

E-mail_addresses: sara.gez.garcia@gmail.com,_sara.gonzalez@usc.es (S. González-García).
}

gases (GHG), mainly derived from fossil fuel combustion [1,2]. Moreover, securing energy supply is a key target [3]; since its demand has soared under the pressure of developing countries, which have increased their production schemes [4]. Therefore, the use of renewable resources, the efficient energy production and the reduction of energy use are priorities on the European political agenda towards a more sustainable future [3]. In this context, the European Commission has adopted the ambitious target to increase the ratio of renewable energy up to $20 \%$ by 2020 [5]. 
Bioenergy is a renewable energy produced from biomass, including energy crops, wood, microbial biomass as well as wastes from household, agricultural, cattle, forestry and industrial activities [6]. Currently, there is a growing interest on the use of biomass for energy purposes in order to satisfy energy requirements all over Europe [7], which would imply lower dependency on imports of fossil fuels for many European Union countries where biomass is a local resource [8].

According to Holm-Nielsen et al. [9], biogas as potential renewable energy source could represent $25 \%$ of all the bioenergy in Europe in the near future. Biogas is a gaseous fuel obtained as a result of the Anaerobic Digestion (AD) of a wide range of organic feedstock [10], giving an answer to the inadequate management of industrial, agricultural and domestic wastes [11,12]. Special interest is being paid on its promotion for several reasons: security of energy supply, economic and market benefits, advantages on production and storage [9].

As a result, many agricultural biogas plants using manure and agricultural products as main feedstock have been recently built in Europe for the final transformation of biogas into electric and thermal energy [13]. The most developed facilities are located in Germany, Denmark, Austria, Sweden [9] and Italy [14]. Focusing on Italy, although the incentive framework for electricity production has been recently revisited, there is still a big interest on production of renewable energy with special emphasis on biogas [15]. In addition, Italy occupies an outstanding position in terms of pig and cattle breeding in Europe [16].

$\mathrm{AD}$ does not only produce biogas but also a digested substrate, commonly referred as digestate. It is a nutrient-rich stream that can be used as organic fertilizer for crop cultivation, which would return nutrients back to the soil in substitution of mineral fertilizers [17-19].

Furthermore, the AD of two or more different feedstock is known as co-digestion. According to the literature, biogas plants that perform co-digestion can achieve up to 10\% higher biogas yield in comparison with those with single feedstock digestion [20], since the synergy between mixture components compensates the lack of certain substrates [21].

Apparently, the co-digestion with wastes could improve the environmental performance of biogas production [2] because only environmental burdens associated with its handling are included but none about its production [19]. It would be necessary to be aware of the quality and quantity of effects associated to biogas production [17].

Life Cycle Assessment (LCA) is a quantitative procedure to evaluate the environmental burdens associated with a product or a process and to identify opportunities to attain environmental advantages [22]. Numerous LCA studies are available in the literature concerning biogas production and use [2,23-25]. In these studies, biogas production systems from different feedstock (mono- and codigestion) as well as their possible applications have been assessed from environmental and energy perspectives, with special attention on GHG emissions and fossil fuel depletion [23,25].

Hartmann [17] evaluated a biogas production system operated with energy crops in combination with cattle and pig manure. The results showed that the most relevant environmental impacts are related not with the biogas system itself but with the agricultural system, mainly derived from the use of fossil fuel and mineral fertilizers. Börjesson and Berglund [23] analyzed the fuel-cycle emissions from a variety of biogas systems. The results showed that the environmental impact of biogas systems largely depends on the raw material digested, the efficiency of the biogas production chain, the uncontrolled loss of methane and the development of the end-use technology. Poeschl et al. [20,25] analyzed the production and utilization of biogas in different scenarios with diverse feedstock, biogas use and digestate processing. The results obtained by these authors indicated a wide range of variations on the potential environmental impacts and energy conversion efficiency depending on the biogas production and utilization pathway selected.

The purpose of this study was to evaluate the environmental impacts and energy requirements associated with a co-digestion process as well as its further transformation into energy. This study is focused on an Italian biogas plant located in San Giorgio di Lomellina (Lombardy) which codigests pig slurry with energy crops for several reasons: 1) the annual production of pig slurry is considerably high in Italy [26,9], 2) maize and triticale silages are among the most suitable energy crops for biogas production $[20,27]$ and, 3) there is a large number of anaerobic digestion plants throughout Italy, most of them located in Lombardy [28].

\section{Materials and methods}

\subsection{Methodology}

LCA is a methodology for the comprehensive evaluation of the impact that a product (good or service) has on the environment throughout its life cycle [22]. This method presents a holistic approach for a comprehensive environmental assessment, following a standardized method which guarantees reproducibility of results $[22,29]$.

\subsection{Goal and scope definition}

The environmental impacts and energy requirements of the biogas production system from the co-digestion of pig slurry and two energy crops (maize and triticale silages) and the subsequent use for electricity and heat generation (bioenergy) were determined. An Italian biogas plant located in San Giorgio di Lomellina (Lombardy) and considered representative of the state-of-the-art was assessed in detail from a cradle-to-gate perspective. All energy and material flows as well as emissions associated were identified and quantified in detail. Moreover, the most critical stages from an environmental point of view (hotspots) were identified and alternatives were proposed in order to reduce the impact and improve the environmental and energy profiles.

\subsection{Functional unit}

The functional unit (FU) expresses the function of the system in quantitative terms and provides the reference to which all the inputs and outputs of the product system are calculated [22]. The function of this system is the production of bioenergy (electricity and heat) by means of the co-digestion of organic feedstock. Thus, the FU chosen to carry out the assessment was $100 \mathrm{kWh}$ of electricity produced $(\mathrm{kWh} / \mathrm{l})$ in a combined heat and power unit (CHP) with pig slurry, maize silage and triticale silage as feedstock of the co-digestion process.

\subsection{System boundaries and definition of the system under assessment}

The representative system under study was based on a state-ofthe-art biogas technology plant and was divided into four subsystems: biomass production (SS1), feedstock transport and processing (SS2), bioenergy production plant (SS3) and digestate management (SS4). The system boundaries and processes considered under assessment are illustrated in Fig. 1. Pig slurry is the main waste of pig breeding activity and its use in $\mathrm{AD}$ plants is a valuable solution for its management. Accordingly, the management of pig 
System boundary

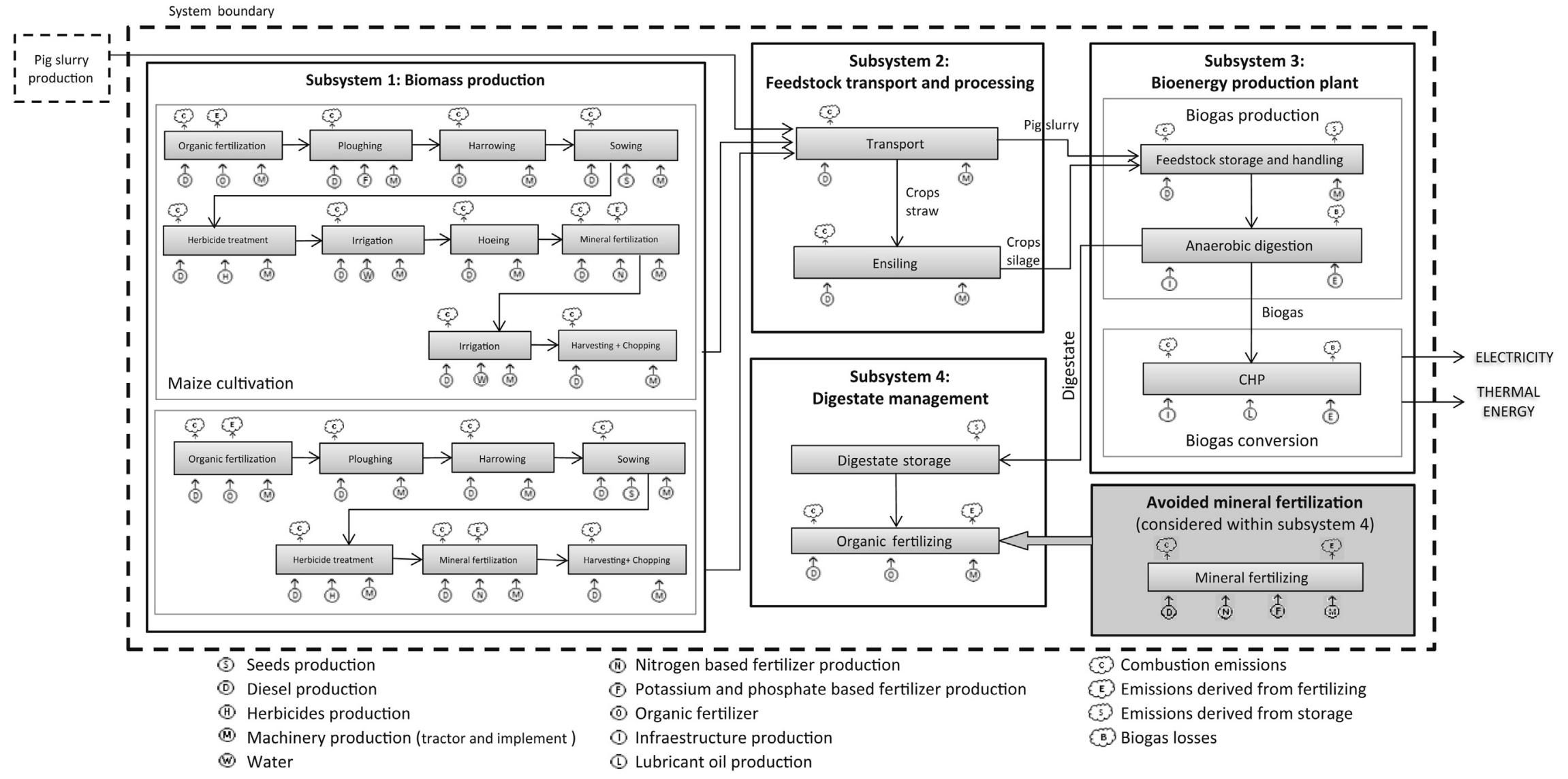

Fig. 1. Flowchart and system boundary of the bioenergy production system under study. 
farms was excluded from the assessment since its operation would not be driven by a change in slurry management.

In Fig. 1, dotted box indicates that this process was not considered within the system boundaries while grayed box indicates avoided process.

\subsubsection{Subsystem 1 (SS1): biomass production}

This subsystem included all the agricultural field operations involved in the maize and triticale cultivation from soil tillage up to the harvesting step. The maize and triticale crops under assessment are exclusively dedicated to the production of biomass for energy purposes [27]. Field activities performed in both crops are ploughing, harrowing, fertilizing, pesticides application, sowing, harvesting and chopping. Contrarily to triticale, maize cultivation also requires irrigation and hoeing operations. More detailed information concerning the cultivation of these crops can be found in González-García et al. [27].

The subsystem boundary included all inputs such as the production of agricultural machinery (tractors and implements), fertilizers (urea, $\mathrm{K}$ and $\mathrm{P}$ based fertilizers for maize and urea and ammonium nitrate for triticale), herbicides (Lumax and S-metolachlor in case of maize and Terbutilazine and Alachlor for triticale), seeds and fossil fuel for operating the agricultural machinery. The uptake of $\mathrm{CO}_{2}$ by photosynthesis was taken into account as well as outputs such as emissions derived from fuel consumption and fertilizers application (ammonia, nitrous oxide, nitrogen gas and phosphate).

\subsubsection{Subsystem 2 (SS2): biomass transport and processing}

In this subsystem, the environmental burdens considered involved all inputs and outputs required for the delivery of the biomass up to the gate of the bioenergy plant and the ensiling operations of the maize and triticale straw.

The transport of feedstock (pig slurry, maize silage and triticale silage) is carried out separately by means of lorries. Pig slurry is delivery daily from pig farms to the bioenergy plant. Only $50 \%$ of the pig slurry needs to be transported, this amount is produced in the surrounding area; accordingly, the distance between pig farms and the bioenergy plant was assumed to be $2.5 \mathrm{~km}$. The remaining $50 \%$ of pig slurry does not need transportation since it is produced very close to the biogas plant. Maize and triticale biomass were transported from nearby fields to the biogas plant (average distance of $1.5 \mathrm{~km}$ ) where ensiling operations took place. All the machinery and diesel required as well as combustion emissions produced from diesel consumption for these processes were included.

\subsubsection{Subsystem 3 (SS3): bioenergy plant operation}

In this subsystem, the environmental burdens included all inputs and outputs required for the bioenergy plant running operations. This subsystem was further divided into two main stages: biogas production from $\mathrm{AD}$ and its conversion into electricity and heat.

Biogas production stage involves feedstock storage and handling as well as the AD process. Storage is performed differently for pig slurry and energy crops. As mentioned, pig slurry is delivery every day from pig farms to the digester. Therefore, derived emissions from its storage were considered almost negligible and were excluded from the system boundaries. Energy crops are stored after the ensiling process in the silos. During this storage, around $2 \%$ of the total mass harvested is lost. For the handling of pig slurry and silages, the production of machinery and diesel required as well as the combustion emissions derived from fossil fuel consumption were taken into account.

$\mathrm{AD}$ is carried out as a single stage process considering a continuous stirred-tank reactor (CSTR) with a total volume of
$2900 \mathrm{~m}^{3}$, working under mesophilic conditions $\left(40{ }^{\circ} \mathrm{C}\right)$ and a retention time of 35-45 days. The organic loading rate (OLR) defined in terms of Volatile Solids (VS) is $1.6 \mathrm{~kg} \mathrm{SV} \mathrm{m}^{-3}$ day $^{-1}$ and the total solid content (dry matter) inside the digester is around $8-$ $9 \%$. The silage is fed into the digester through a screw auger ( $40 \mathrm{~kW})$ while the pig slurry is loaded by means of a lobe pump $(20 \mathrm{~kW})$. The feeding operation is repeated every hour. The digester has four submerged mixers with electrical engines ( $13 \mathrm{~kW}$ each), a pump for the digestate $(15 \mathrm{~kW})$ and 5 pumps ( $0.5 \mathrm{~kW}$ each) for hot water circulation in the heat exchangers. The biogas treatment is carried out by a refrigeration unit $(15 \mathrm{~kW})$ that cools down the biogas temperature and removing up the water vapor. In addition, biogas is desulphurized by means of a washing water solution ( $8 \%$ is $\mathrm{NaOH}$ ). In the $\mathrm{AD}$ process, both electricity and heat are required. Electricity is mainly consumed in the loading operations, in the digester and in the chiller. It is taken directly from the Italian national grid. Thermal energy is needed to heat up the biomass inside the digester and it is recycled from the gas engine.

In the biogas conversion stage, the produced biogas is used in a CHP generating electricity and heat. The electric engine power is $500 \mathrm{~kW}$ (electric efficiency 38.5\%). Since the heat is recovered both from the engine (water and oil cooling jacket) and the exhaust gases, the thermal power is $623 \mathrm{~kW}$ (thermal efficiency 48\%). Usually only the thermal energy for heating the digesters is recovered. Nevertheless, in the plant under study, although the heat recovered from the engine jackets would be enough for heating biomass, also the heat from gases is recovered. The total electricity produced is assumed to be supplied to the Italian national grid. Concerning the thermal energy, except selfconsumption, it is wasted (dissipated by means of dry-coolers). All inputs and outputs required for the CHP operation such as electricity and lubricant oil were included. The electricity is provided by the national grid. Also, the derived emissions from the cogeneration process (such as nitrogen oxides, carbon monoxide, carbon dioxide, methane, non-methane volatile organic compounds, nitrous oxide and sulfur dioxide) were considered.

In addition, biogas losses in this subsystem are caused by leakages in valves and pipe connections; thus, around $1.5 \%$ of the total volume of produced biogas is emitted into the atmosphere ( $1 \%$ from the digestion plant and $0.5 \%$ from the gas engine). Production of infrastructure of the bioenergy production plant was also considered within the subsystem boundaries.

\subsubsection{Subsystem 4 (SS4): digestate management}

In the $\mathrm{AD}$ process digestate is also co-produced. This subsystem involves both digestate storage and its application as organic fertilizer on arable land.

Digestate is stored in an open tank for an average period of 150 days (a storage time of 180 days is foreseen). Residual biogas production as well as other emissions (ammonia, nitrous oxide and nitrogen) occurs during the digestate storage, due to the fact that the digestate still contains some undigested organic matter [30]. Thus, these emissions were also taken into account within the system boundaries. Leaching during storage was assumed to be negligible, assuming that the tank is fully sealed.

Digestate contains N, P and $\mathrm{K}$ compounds in different concentrations, which are also present in mineral fertilizers. Therefore, the digestate can substitute chemical fertilizers (e.g. ammonium nitrate, triple superphosphate and potassium sulfate) using an amount proportional to their contents of active ingredients [20]. The digestate application as an organic fertilizer in arable land was taken into account within the system boundaries together with the consequently avoided mineral fertilization $(\mathrm{N}, \mathrm{P}, \mathrm{K})$. The requirements of agricultural machineries and the corresponding emissions from fossil fuel consumption were included as well as the 
emissions derived from digestate and mineral fertilizers application on field (ammonia, nitrous oxide, nitrogen, nitrate and phosphate).

\subsection{Allocation procedure}

Allocation is one of the most critical issues in LCA. It consists on partitioning the input and the output flows of a unit process among the products [22]. In the system under assessment, whenever possible, allocation procedure was avoided following ISO standards.

During AD (first stage of SS3), biogas and digestate are coproduced. The biogas was considered as the main product although the digestate is used as an organic fertilizer reducing the consumption of mineral fertilizers [9]. An avoided product perspective was considered in this study. Therefore, the application of digestate without any prior treatment was assumed as base case and the derived emissions were calculated. Impacts derived from the production, transportation and application of the avoided mineral fertilizers were also included within the subsystem boundaries as base case. The quantity of mineral fertilizers substituted was defined considering the nutrients content within the digestate.

Concerning the cogeneration plant (second stage of SS3), heat is partially recirculated to the digesters while the remaining fraction is waste. The produced electricity is sold to the national grid. Therefore, the environmental loads were totally allocated to the electricity production as base case. Alternative allocation approaches were proposed for assessment and are discussed below.

\subsection{Inventory data acquisition}

The most effort-consuming step in the execution of LCA studies is the collection of inventory data in order to build the Life Cycle Inventory (LCI). A high quality data (input and output) is essential to make a reliable evaluation. For this study they were collected from different sources and procedures.

Inventory data related with the maize and triticale production processes (SS1) were taken from the literature [27]. These authors managed real data coming from the same site under analysis. In the mentioned study, field emissions derived from fertilizers application were also estimated. The nutrient emissions rates are variable depending on the soil type, the climatic conditions as well as the agricultural management practices [31]. Direct emissions derived from herbicides application were not included [27] due to the absence of data required to calculate the fractions of applied herbicides reaching the environmental compartments (i.e. air, surface water and groundwater). Carbon stored by the biomass was considered equal to the carbon content of the biomass $(42.1 \%$ for triticale and $41.5 \%$ for maize, calculated on dry mass). More detailed information concerning these calculations can be found in González-García et al. [27]. All these data together are shown in Table 1.

LCI data for the foreground system, such as primary and sitespecific data, were mainly collected directly on the bioenergy production plant by means of surveys and interviews with workers. Table 2 presents the inputs and outputs related with the transport and processing of the feedstock (SS2). Biogas production requires feedstock, water, diesel, electricity, heat and sodium hydroxide and produces biogas and digestate. Biogas conversion into bioenergy involves inputs such as electricity and lubricant oil and outputs such as electricity and heat as well as CHP derived emissions (nitrogen oxides, carbon monoxide, carbon dioxide, methane, nonmethane volatile organic compounds, nitrous oxide and sulfur dioxide). A detailed description of LCI data corresponding to SS3 is reported in Table 3 . In addition, technical information related with operation and maintenance of both the digesters and the CHP was directly collected too.
Table 1

Global inventory data (per $100 \mathrm{kWh}_{\mathrm{el}}$ ) for Subsystem 1.

\begin{tabular}{|c|c|c|c|}
\hline Input from technosphere & \multicolumn{3}{|c|}{ Output to technosphere } \\
\hline Materials and fuels & \multicolumn{3}{|c|}{ Products and co-products } \\
\hline Maize seed & $9.35 \mathrm{~g}$ & Maize straw & $161.5 \mathrm{~kg}$ \\
\hline Triticale seed & $393 \mathrm{~g}$ & Triticale straw & $110.5 \mathrm{~kg}$ \\
\hline Lumax & $0.013 \mathrm{~kg}$ & & \\
\hline Metolachlor & $0.003 \mathrm{~kg}$ & & \\
\hline Terbutilazine & $0.008 \mathrm{~kg}$ & & \\
\hline Atrazine & $0.008 \mathrm{~kg}$ & & \\
\hline Urea & $1.22 \mathrm{~kg}$ & & \\
\hline Fertilizer $(\mathrm{P})$ & $0.32 \mathrm{~kg}$ & & \\
\hline Fertilizer (K) & $0.32 \mathrm{~kg}$ & & \\
\hline Ammonium nitrate & $0.18 \mathrm{~kg}$ & & \\
\hline Digestate & $260 \mathrm{~kg}$ & & \\
\hline Diesel & $0.33 \mathrm{~kg}$ & & \\
\hline \multicolumn{2}{|l|}{ Input from environment } & \multicolumn{2}{|c|}{ Output to environment } \\
\hline \multirow{6}{*}{$\begin{array}{l}\text { Resource } \\
\text { Carbon dioxide } \\
\text { Water }\end{array}$} & \multicolumn{3}{|c|}{ Emissions to air } \\
\hline & $158 \mathrm{~kg}$ & Ammonia & $87.14 \mathrm{~g}$ \\
\hline & $9.04 \mathrm{~m}^{3}$ & Nitrous oxide & $12.8 \mathrm{~g}$ \\
\hline & & Nitrogen & $85.25 \mathrm{~kg}$ \\
\hline & & Emissions to water & \\
\hline & & Phosphate & $0.003 \mathrm{~kg}$ \\
\hline
\end{tabular}

The production of biogas during the storage of digestate widely ranges, from $5 \%$ up to $20 \%$, depending on the substrate properties and operational conditions [20,23,32]. According to Gioelli et al. [28], the biogas produced during the digestate storage accounts around $9.2 \%$ of the total biogas, in agreement with other literature $[20,23,33]$. Additional derived emissions resulting from the digestate storage were also calculated according to De Vries et al. [2]. As previously mentioned, the digestate could be used as fertilizer on arable lands. The amount of mineral fertilizers that could replace the digestate was calculated taking into account the fertilizer replacement values. In the case of digestate, the replacement value for $\mathrm{N}$ was assumed to be $65 \%$ and $100 \%$ for $\mathrm{P}$ and $\mathrm{K}$, respectively. The derived emissions of digestate and mineral fertilizers application were calculated with the emissions factors proposed by Brentrup et al. [31]. In addition, the use of digestate as well as P fertilizers involves phosphate emissions into water estimated according to the emission rate proposed by Rossier [34], equal to $0.01 \mathrm{~kg} \mathrm{P}-\mathrm{PO}_{4}{ }^{-3} \mathrm{~kg}^{-1}$ of applied P. Inventory data regarding SS4 is presented in Table 4.

Background data regarding the production of the different inputs, such as: production of fertilizers, herbicides, agricultural machineries, lorries, electricity, heat, fossil fuels and plant infrastructure as well as CHP operating and fossil fuel combustion derived emissions were taken from the ecoinvent ${ }^{\circledR}$ database [35-39].

\section{Results}

Among the steps defined within the life cycle impact assessment stage of the LCA methodology [22], only classification and characterization stages were undertaken here. The environmental profile was estimated by using the characterization factors reported by the CML baseline 2000 method [40] for six impact categories:

Table 2

Global inventory data (per $100 \mathrm{kWh}_{\mathrm{el}}$ ) for Subsystem 2 .

\begin{tabular}{llll}
\hline Input from technosphere & \multicolumn{3}{c}{ Output to technosphere } \\
\hline Materials and fuels & \multicolumn{3}{c}{ Products and co-products } \\
Maize straw (from SS1) & $161.5 \mathrm{~kg}$ & Maize silage (to SS3) & $161.5 \mathrm{~kg}$ \\
$\quad$ Triticale straw (from SS1) & $110.5 \mathrm{~kg}$ & Triticale silage (to SS3) & $110.5 \mathrm{~kg}$ \\
$\quad$ Diesel & $0.12 \mathrm{~kg}$ & & \\
Transport & & & \\
$\quad$ Lorry 16-32t & $0.7 \mathrm{t} \mathrm{km}$ & \\
\hline
\end{tabular}


Table 3

Global inventory data (per $100 \mathrm{kWh}_{\mathrm{el}}$ ) for Subsystem 3.

\begin{tabular}{|c|c|c|c|}
\hline Input from technosphere & & \multicolumn{2}{|c|}{ Output to technosphere } \\
\hline \multicolumn{2}{|l|}{ Materials and fuels } & \multicolumn{2}{|c|}{ Products and co-products } \\
\hline Pig slurry & $233.3 \mathrm{~kg}$ & Digestate & $1083 \mathrm{~kg}$ \\
\hline Maize silage (from SS2) & $161.5 \mathrm{~kg}$ & Electricity & $100 \mathrm{kWh}$ \\
\hline Triticale silage (from SS2) & $110.5 \mathrm{~kg}$ & Heat & $80.5 \mathrm{kWh}$ \\
\hline Diesel & $0.28 \mathrm{~kg}$ & & \\
\hline Sodium hydroxide & $0.008 \mathrm{~kg}$ & & \\
\hline \multicolumn{4}{|l|}{ Energy } \\
\hline Electricity & $8.46 \mathrm{kWh}$ & & \\
\hline Input from environment & \multicolumn{3}{|c|}{ Output to environment } \\
\hline \multirow{8}{*}{$\begin{array}{r}\text { Resource } \\
\text { Water }\end{array}$} & \multicolumn{3}{|c|}{ Emissions to air } \\
\hline & & gen oxides & $0.018 \mathrm{~kg}$ \\
\hline & & n monoxide & $0.057 \mathrm{~kg}$ \\
\hline & & n dioxide & $97 \mathrm{~kg}$ \\
\hline & & ane & $0.054 \mathrm{~kg}$ \\
\hline & & & $0.002 \mathrm{~kg}$ \\
\hline & & Is oxide & $0.003 \mathrm{~kg}$ \\
\hline & & dioxide & $0.025 \mathrm{~kg}$ \\
\hline
\end{tabular}

abiotic depletion potential (ADP), acidification potential (AP), eutrophication potential (EP), global warming potential (GWP), ozone layer depletion potential (ODP) and photochemical oxidation potential (POFP). An energy analysis was also carried out based on the cumulative non-renewable fossil and nuclear energy demand (CED), which represents the entire energy demand of the global life cycle. This indicator was computed according to Hischier [41], and it was considered as an additional impact category.

Table 5 summarizes the LCA characterization results for the different subsystems under study per functional unit that is, $100 \mathrm{~kW}_{\mathrm{el}}$. In the presented results, positive values are indicative of environmental burdens whereas negative values signify environmental credits or benefits accrued from carbon dioxide uptake and the substitution of mineral fertilizers.

In order to facilitate the results understanding, Fig. 2 displays the relative contributions of each subsystem to the global environmental results for the system under assessment.

As observed in Fig. 2, relevant differences on the contributions from subsystems can be identified. According to these results, the biomass production (SS1) shows high influence over the environmental profile, especially in terms of AP and EP, with contributions of $45 \%$ and $61 \%$, respectively. These results are mostly related with emissions derived from fertilizers application. Oppositely, this subsystem achieves a positive effect in GWP as a result of the $\mathrm{CO}_{2}$ uptake by photosynthesis. Thus, the emission of $142 \mathrm{~kg} \mathrm{CO}_{2}$ eq per functional unit is avoided.

Table 4

Global inventory data (per $100 \mathrm{kWh}_{\mathrm{el}}$ ) for Subsystem 4 .

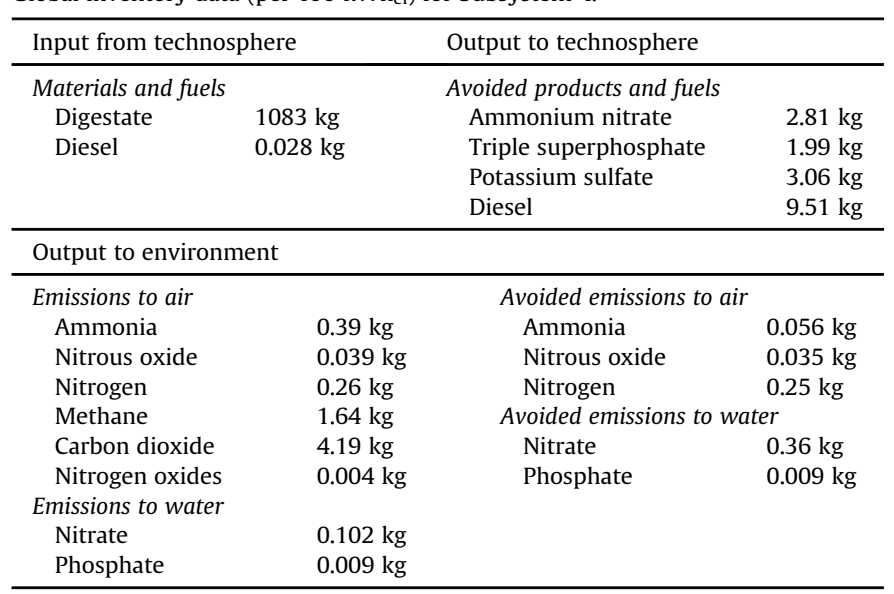

Table 5

Characterization results corresponding to the production of $100 \mathrm{~kW}_{\mathrm{el}}$ from biogas.

\begin{tabular}{lllllll}
\hline \multicolumn{2}{l}{ Category Unit } & Total & SS1 & SS2 & SS3 & SS4 \\
\hline ADP & $\mathrm{kg} \mathrm{Sb} \mathrm{eq}$ & -0.016 & 0.097 & 0.008 & 0.050 & -0.171 \\
$\mathrm{AP}$ & $\mathrm{kg} \mathrm{SO}_{2}$ eq & 0.658 & 0.297 & 0.006 & 0.083 & 0.272 \\
$\mathrm{EP}$ & $\mathrm{kg} \mathrm{PO}_{4}{ }^{-3}$ eq & 0.124 & 0.076 & 0.002 & 0.012 & 0.034 \\
$\mathrm{GWP}$ & $\mathrm{kg} \mathrm{CO}_{2}$ eq & -24.25 & -141.94 & 1.078 & 112.34 & 4.28 \\
$\mathrm{ODP}$ & $\mathrm{kg} \mathrm{CFC}^{-11}$ eq & $-7.7 \cdot 10^{-7}$ & $1.43 \cdot 10^{-6}$ & $1.29 \cdot 10^{-7}$ & $8.08 \cdot 10^{-7}$ & $-3.13 \cdot 10^{-6}$ \\
$\mathrm{POFP}$ & $\mathrm{kg} \mathrm{C}_{2} \mathrm{H}_{4}$ & 0.011 & 0.003 & $2.5 \cdot 10^{-4}$ & 0.006 & 0.001 \\
$\mathrm{CED}$ & $\mathrm{MJ} \mathrm{eq}$ & 24.46 & 287.25 & 19.19 & 109.78 & -391.76 \\
\hline
\end{tabular}

The bioenergy production plant (SS3) significant contributes to the environmental impact in categories such as GWP (43\%) and POFP (59\%), mostly related with emissions produced in the gas engine and biogas losses.

SS4 involves digestate storage and its utilization as an organic fertilizer. Thus, the use (and corresponding production) of mineral fertilizers is avoided. As reported in Table 5, it ends up in environmental benefits in terms of ADP, ODP and CED. On the other hand, significant environmental impacts were perceived in this subsystem in terms of AP (41\%) and EP (28\%) (Fig. 2), mainly due to emissions derived from digestate storage and application.

Next, a detailed assessment per subsystem was performed in order to identify in detail the responsible processes of these environmental results.

\subsection{SS1 - biomass production subsystem}

According to the results reported in Table 5 and Fig. 2, this subsystem, which comprises the agricultural activities performed in the farm, the production of agrochemicals and all derived field emissions, shows remarkable contributions in all categories selected. The detailed assessment (Fig. 3) points out that, regardless the category, the contributions from maize cultivation are greater than these from triticale. It is related with more intensive agricultural practices in maize than in triticale cultivation and because per functional unit it is digested more maize silage than triticale silage (ratio 1.5:1).

According to González-García et al. [27], agricultural activities are significant for both energy crops cultivation in categories such as ADP, ODP, POFP and CED (46-71\% regarding maize and $34-48 \%$ for triticale cultivation). It is mainly due to diesel requirements in agricultural machinery and derived combustion emissions. Within the different activities involved in maize cultivation, the irrigation process presents the highest contribution ratio, mainly due to energy requirements. Since triticale cultivation does not need irrigation, the harvesting process was identified as the main environmental hotspot due to the large consumption of diesel in this

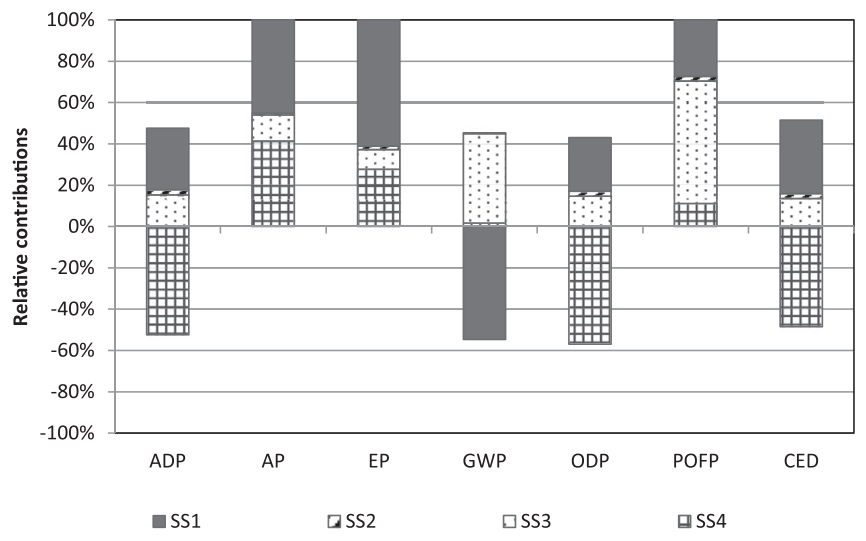

Fig. 2. Relative contributions from subsystems involved to each impact category. 


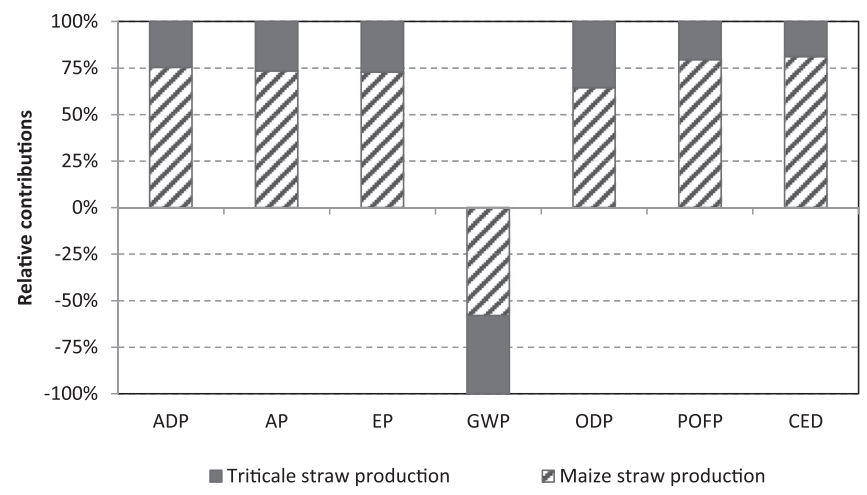

Fig. 3. Breakdown of contributions from processes involved in Subsystem 1.

process. The production of mineral fertilizers (especially urea in case of maize cultivation and ammonium nitrate and urea in case of triticale production) required for fertilizing has also an important role in these categories (25-48\% for maize and $29-44 \%$ for triticale) due to their highly intensive energy production process. Field emissions derived from the application of fertilizers considerably contribute to AP and EP (77 and 73\% for maize and 75 and $63 \%$ for triticale, respectively). It is essentially associated with ammonia and phosphate derived emissions. Concerning GWP, emissions from the combustion of diesel by the agricultural machinery are the main source of GHG. As mentioned before, $\mathrm{CO}_{2}$ uptake by photosynthesis offsets the GHG emitted throughout the cultivation system, ending up into a positive effect for GWP (Fig. 3).

\subsection{SS2 - feedstock transport and processing subsystem}

According to Fig. 2, SS2 plays a minor role in the environmental characterization of the system under study in comparison with the remaining subsystems. This subsystem involves both feedstock transport and energy crops ensiling process. As can be seen in Fig. 4, the ensiling process is largely the main contributor to this subsystem for all the environmental impact (from 90 in ODP to $94 \%$ in POFP). Paying more attention, maize ensiling presented higher environmental impact than triticale ensiling for all categories. This is due to higher ratio of maize silage fed in the digester comparing with triticale silage.

\subsection{SS3 - bioenergy production plant subsystem}

With regard to the bioenergy production plant (SS3), Fig. 5 shows the relative contributions from each process involved in this subsystem for each impact category selected.

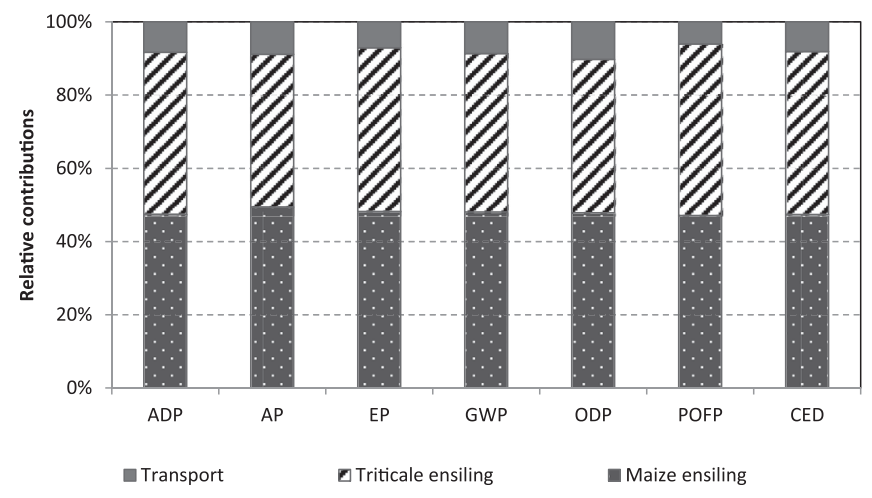

Fig. 4. Breakdown of contributions from processes involved in Subsystem 2.

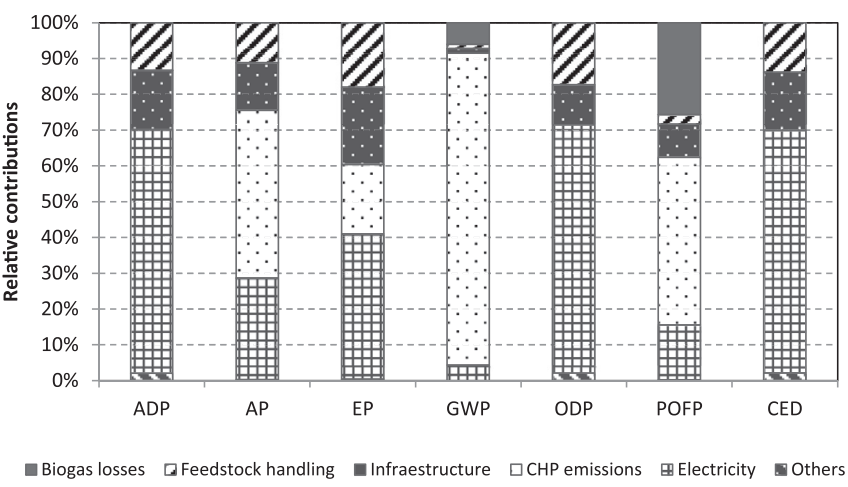

Fig. 5. Breakdown of contributions from processes involved in Subsystem 3.

Electricity is required to run the bioenergy plant in different processes involved in both biogas production and conversion. As reported before, this electricity is taken from the Italian grid. Its production arises as an important contributor for almost all categories selected, especially in terms of ADP, ODP and CED, providing around the $68 \%$ of the total impact produced by this subsystem. It is because the Italian energy profile is highly composed of nonrenewable energy sources. More than $90 \%$ of the electricity consumption in SS3 is due to biogas production stage, mainly in loading operations, in the digester and in the chiller. Biogas combustion derived emissions that take place in the CHP displays a remarkable contribution in terms of AP (47\%), EP (19\%), GWP (87\%) and POFP (47\%), mainly motivated by carbon dioxide emissions derived from this combustion. In the bioenergy production plant, biogas losses derive from different types of leakage in facilities such as in pipes and valves connections (1.5\% of biogas production). These emissions contribute with 6\% in GWP and 26\% in POFP mainly due to methane emissions. Feedstock (pig slurry and energy crops silage) handling operations present small contributions, ranging from 1\% in GWP to $18 \%$ in EP. Diesel consumption in machinery involved in this process is the main responsible of these results. As indicated in the description of the system boundaries, the infrastructure production was also taken into account in this study. It presents a minor influence in the environmental profile (from $1 \%$ in GWP to $22 \%$ in EP), mainly due to the activities required during maintenance operations.

\subsection{SS4 - digestate management subsystem}

Fig. 6 displays the relative contributions from processes involved in the digestate management (SS4). This subsystem involves digestate storage, digestate application as organic fertilizer

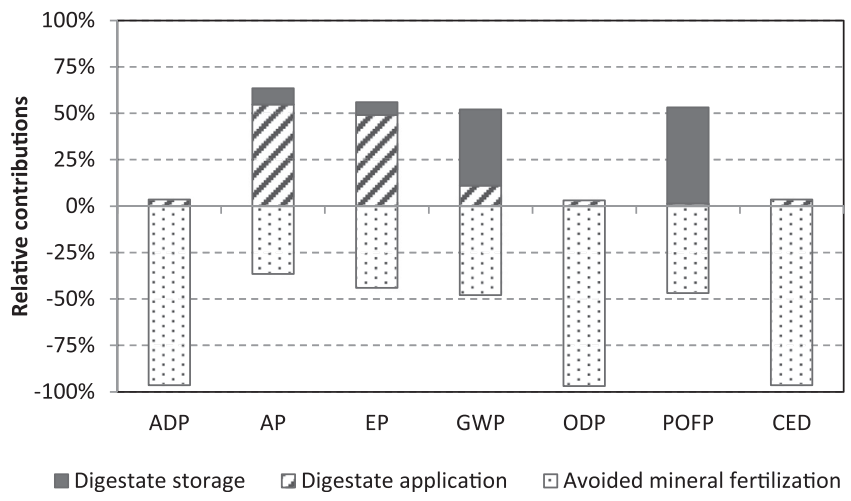

Fig. 6. Breakdown of contributions from processes involved in Subsystem 4. 
and derived avoided production and application of mineral fertilizers. According to the results displayed in Fig. 6, digestate storage arises as the main source of impacts concerning GWP and POFP, with contributions of $41 \%$ and $52 \%$, respectively. Derived emissions from digestate storage, such as methane, carbon dioxide and nitrous oxide are the main contributing substances in GWP. In addition, digestate storage emissions also contribute in AP (9\%) and EP (7\%). Environmental burdens derived from digestate application on agricultural land remarkably contributed to AP (55\%) and EP (49\%), mainly related with emissions of ammonia for AP and nitrate for EP which occurs during digestate application. These emissions have also an influence on GWP with a contribution of $11 \%$ due to nitrous oxide emission.

As mentioned, a positive effect is achieved due to the consideration of avoiding the application of mineral fertilizers in almost all categories. In Fig. 7 the contributions derived from avoiding mineral fertilizers application are assessed in more detail. The fertilizers production is the most important contributor, ranging from $39 \%$ for EP to $89 \%$ for POFP. This is motivated by the fact that the fertilizers production (especially ammonium nitrate) is associated with large energy requirements. In addition, field emissions derived from mineral fertilizers application considerably contribute to impact categories such as AP (24\%), EP (51\%) and GWP (20\%) due to emissions such as ammonia in AP, ammonia, nitrate and phosphate in EP and nitrous oxide in GWP. It is also interesting to point out the role of fertilizing process in all the categories selected. While digestate only is applied once, mineral fertilizers need to be applied three times (once per mineral fertilizer). Thus, agricultural machinery needed as well as fossil fuel requirements are higher for mineral fertilizers application. As a result, fertilizing process supposes contributions between $11 \%$ in POFP and 19\% in CED.

\section{Discussion}

Renewable energies play a key role in the mitigation of GHG emissions and energy security [25]. The anaerobic co-digestion of organic wastes and energy crops for biogas production can be considered as one of the most useful decentralized sources of energy supply [42]. Moreover, considering the waste-to-energy transformation, anaerobic processes can be considered a way to reduce organic wastes [42]. In addition, biogas systems are interesting because not only biogas and electricity are produced, but also other added value by-products such as digestate and heat.

Several LCA studies have analyzed the environmental benefits and weaknesses of mono- and co-digestion to produce biogas, which can be further converted into electric energy [2,19,25,43]. These authors have reported that the environmental impact and biogas yield considerably depend on factors such as raw materials

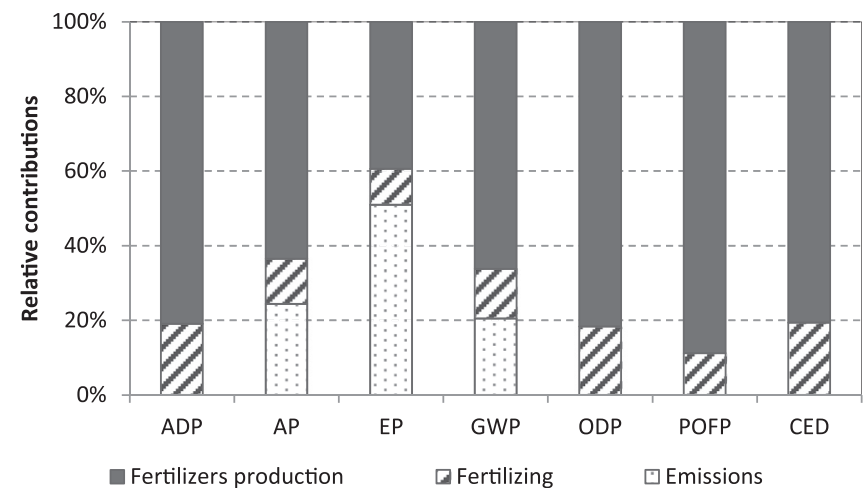

Fig. 7. Relative contribution of each process within mineral fertilizers application. digested (such as grass, maize silage, pig manure, food and industrial wastes), energy efficiency, uncontrolled losses of methane and differences on system boundaries definition (mainly the consideration or not of avoided products). According to De Vries et al. [2], the co-digestion increased the bioenergy production, which would make the use of wastes as co-substrate the best alternative. Dressler et al. [43] evidenced the influence of local factors, such as soil and climate conditions, on the environmental impacts associated with the production of maize silage. Thus, wastes (agricultural, municipal solid or food residues) have been found in many studies as a potential opportunity to reduce the environmental burdens derived from biogas systems $[2,19,20]$.

It is possible to make a comparison of the results obtained in this study for the impact categories of GWP, AP and EP with other LCA reports. When focusing on figures from the different studies, important differences, especially in terms of GWP, are observed. Börjesson and Berglund [19] reported values for the GWP ranging from 15.5 to $35 \mathrm{~g} \mathrm{CO}_{2}$ eq per $\mathrm{MJ}$ of bioenergy produced (heat and electricity). Uncontrolled methane emissions that may occur derived from pumping leakage and digestate storage were the main contributing substance. Nitrous oxide emissions derived from manure storage and mineral fertilizers application are also remarkable. Dressler et al. [43] reported results ranging from 0.058 to $0.18 \mathrm{~kg} \mathrm{CO} 2$ eq per $\mathrm{kWh}_{\mathrm{el}}$. Credits from avoiding mineral fertilizers production due to the use of digestate and from sharing surplus heat were considered in that study, which contributed to considerably reduce GHG emissions. Poeschl et al. [20,25] and De Vries et al. [2] reported values for GWP ranging from -120 to $105 \mathrm{~kg}$ $\mathrm{CO}_{2}$ eq per ton of feedstock digested. The main reason of this wide range of values is associated with the consideration or not within the system boundaries of: i) diffuse emissions derived from storage activities and ii) the production of substituting product which replace the co-substrate.

Regardless the functional unit considered, our results $(-30 \mathrm{~g}$ $\mathrm{CO}_{2}$ eq per $\mathrm{MJ}$ of bioenergy, $-0.24 \mathrm{~kg} \mathrm{CO} 2$ eq per $\mathrm{kWh}_{\mathrm{el}}$ or $-14 \mathrm{~kg}$ $\mathrm{CO}_{2}$ eq per ton of feedstock digested) are slightly different. As mentioned before, the $\mathrm{CO}_{2}$ uptake and emissions derived from biogas combustion were the main factors affecting these values (Fig. 2). Thus, differences on the feedstock processed, the system boundaries, the allocation procedure and the assessment methodology have influence on the results and explain the variations in relation with other studies.

Regarding other categories, remarkable differences have also been identified. In terms of AP and EP, Börjesson and Berglund [19] reported $0.065-0.175 \mathrm{~g} \mathrm{SO}_{2}$ eq and $0.009-0.65 \mathrm{~g} \mathrm{PO}_{4}{ }^{-3}$ eq per MJ of bioenergy. According to these authors, these categories were significantly affected by the emissions of nitrate and ammonia caused by differences on cropping practices and wastes handling. Dressler et al. [43] considered $1 \mathrm{kWh}_{\mathrm{el}}$ as functional unit and reported results of $1.62-1.94 \mathrm{~g} \mathrm{SO}_{2}$ eq and $0.33-0.40 \mathrm{~g} \mathrm{PO}_{4}^{-3}$. Emissions derived from the CHP and digestate application were found as the most important sources of environmental impact in both categories. Poeschl et al. [25] and De Vries et al. [2] set the results per ton of digested feedstock, achieving considerably differences ranging from -0.33 to $3.5 \mathrm{~kg} \mathrm{SO}_{2}$ eq. The consideration of the substituting product manufacture, land use and carbon storage changes by De Vries et al. [2] considerably contributed to these so variable results.

Once again, in spite of the functional unit chosen, important differences were identified in terms of $\mathrm{AP}\left(0.8 \mathrm{~g} \mathrm{SO}_{2}\right.$ eq per MJ of bioenergy, $6.6 \mathrm{~g} \mathrm{SO}_{2}$ eq per $\mathrm{kWh}_{\mathrm{el}}, 0.37 \mathrm{~kg} \mathrm{SO}$ eq per ton of feedstock) and $\mathrm{EP}\left(0.15 \mathrm{~g} \mathrm{PO}_{4}{ }^{-3}\right.$ eq per $\mathrm{MJ}$ of bioenergy, $1.24 \mathrm{~g} \mathrm{PO}_{4}{ }^{-3}$ eq per $\left.\mathrm{kWh}_{\mathrm{el}}\right)$. Differences in the feedstock used and the selection of the system boundaries were responsible of these results. As previously indicated, derived emissions from fertilizers (SS1) and 
digestate application (SS4) were the main contributors in our study to both impact categories.

The use of digestate as an organic fertilizer is an interesting alternative since it avoids the production of mineral fertilizers and it is a way to valorize an industrial residue. However, special attention must be paid on the agricultural area where it is applied, specifically in Italy. In Northern Italian regions are designated several Nitrate Vulnerable Zones (NVZ) due to the nitrate concentration levels in surface and ground waters and trophic status of surface waters [44]. Therefore, there is a limit on the amount of nitrogen (in $\mathrm{kg}$ ) that can be applied per ha and year from organic fertilizers such as manure ( $170 \mathrm{~kg} \mathrm{~N} \mathrm{ha}^{-1}$ year $^{-1}$ ) [45]. The cropping systems and management regimes, climatic conditions and soil characteristics are variables that must be taken into account. In the calculations of SS4, it was considered the application of the amount of digestate which contains $135 \mathrm{~kg}$ of nitrogen per hectare and per year, according to Eurostat [46]. Therefore, the assumptions made in this study fulfill the legal restrictions established.

\subsection{Sensitivity analysis}

A sensitivity analysis was conducted to assess the influence of the selection of important parameters in the biogas system. A comparison between alternative scenarios and the base case was performed in order to check the strength of the results.

\subsubsection{Methane losses}

The GHG flow associated with the biogas system is directly affected by uncontrolled methane emissions. The average methane emissions rate was reported to be between $1.7 \%$ and $5.2 \%$ of methane yield under normal operating conditions [47]. In our case study (base scenario), 1.5\% of methane produced is lost according to specifications of the biogas plant under assessment.

Methane emissions increase the amount of GHG released to the atmosphere and also reduce production yield. These facts were taken into account in three alternative scenarios which were compared with the base scenario.

- Scenario A: No methane losses with the corresponding increase in the production of electricity and heat.

- Scenario B: $3 \%$ of methane is lost with the associated reductions in the production of electricity and heat and increase of methane and carbon dioxide emissions.

- Scenario C: $5 \%$ of methane is lost with the corresponding values of electricity and heat production and emissions.

The results of the sensitivity analysis are outlined in Fig. 8. As shown, the assumed changes in uncontrolled emissions affect differently the impact categories. While ADP, AP, EP, ODP and CED showed almost no influence, GWP and POFP presented larger effects. In the base scenario, around $24 \mathrm{~kg} \mathrm{CO}_{2}$ eq per functional unit are saved. When no methane losses are considered (scenario A), this value increases to $32 \mathrm{~kg} \mathrm{CO}$ eq per functional unit. This positive effect achieved in terms of GWP decrease when $3 \%$ or $5 \%$ of the methane produced is released to the atmosphere. Then, 15 and $4 \mathrm{~kg}$ $\mathrm{CO}_{2}$ eq per functional unit are saved, respectively. Regarding POFP, reductions of $11 \%$ are achieved in scenario $A$ in comparison with the base scenario. Increments of $11 \%$ and $27 \%$ should be obtained in scenarios $B$ and $C$ respectively due to the increase of uncontrolled biogas emissions.

\subsubsection{Production of heat and electricity}

As previously mentioned, electricity and heat are co-produced from biogas in the bioenergy plant (SS3). The electricity produced is directly injected into the Italian national grid as base line, while

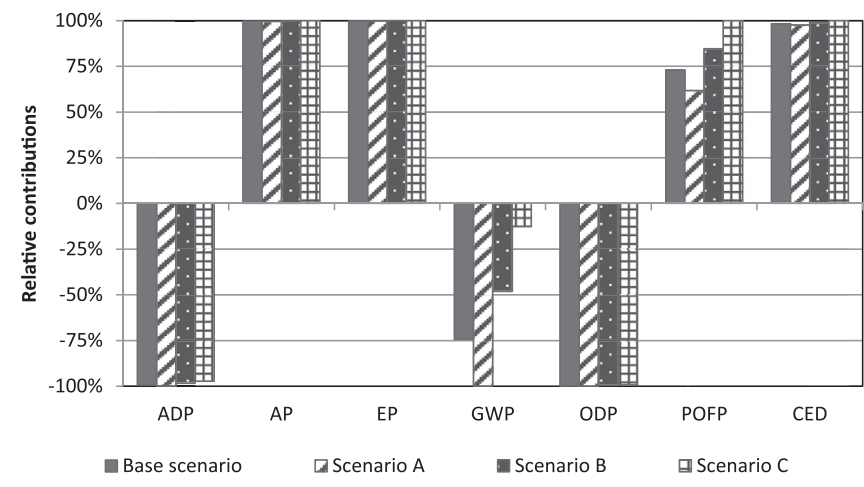

Fig. 8. Comparative environmental and energy results derived from the sensitive analysis on the methane losses.

the excess of heat over self-consumption (35.5\%) is considered as waste (base scenario). However, the amount of surplus heat from biogas could avoid the production of an equivalent amount of heat from a non-renewable source such as natural gas. In the same way, it could be considered that the amount of electricity generated from the biogas could replace the same amount of electricity produced in the Italian grid. The allocation method also highly affects the system profile. In the base scenario, no allocation approach for electricity and heat was considered and all the environmental burdens were directly allocated to the electricity production. However an allocation approach could be assumed if the surplus heat is not considered as waste. An energy based allocation was proposed in order to compare the results with base case. Thus, a sensitivity analysis was performed taking into account all these mentioned considerations. The proposed scenarios for assessment and comparison with the base scenario are the following:

- Scenario D: This scenario was designed considering the avoided heat production from natural gas within the system boundaries.

- Scenario E: This scenario considers not only the avoided heat production from natural gas but also the avoided production of electricity in the Italian grid.

- Scenario F: An energy allocation between the electricity and heat produced in the bioenergy plant was assumed in this alternative scenario.

As shown in Fig. 9, all impact categories evaluated were highly influenced by these alternative scenarios. Scenario $\mathrm{F}$ affects the impact categories to a similar extent: $55 \%$ of impact is reduced when an energy allocation is performed. AP and EP displayed a similar behavior for scenarios D and E. For these categories, the effect of considering avoided heat (scenario D) is almost

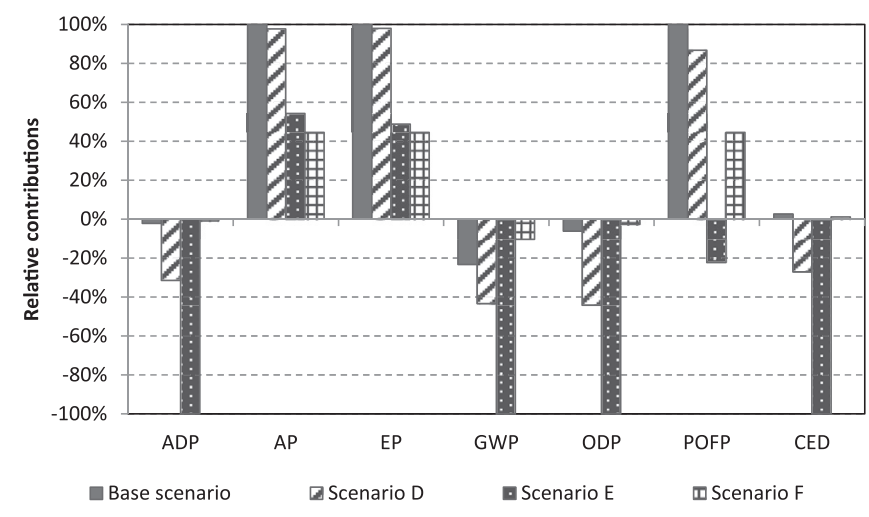

Fig. 9. Sensitive analysis results for electricity and heat production. 
negligible, but the outcome of avoided both heat and electricity (scenario E) achieve $46 \%$ of impact reduction in terms of AP and $51 \%$ in terms of EP. These good results obtained by avoided electricity are mainly due to the high ratio of non-renewable sources in the Italian electric profile (more than 65\% is produced from non-renewable sources, mainly natural gas, oil and hard coal). Moreover, important environmental savings are achieved for ADP, GWP and ODP in scenario D due to avoided heat production from natural gas. Higher environmental burdens were saved regarding these impact categories when avoided Italian electricity production is also included (scenario E). Regarding POFP, a similar behavior was observed. An appreciable reduction on this impact category $(\sim 13 \%)$ is achieved if avoided heat from natural gas is included within the system boundaries (scenario D). Environmental benefits were achieved in scenario $\mathrm{E}$, due to avoiding fossil-based heat and electricity.

Concerning CED, savings of 331 and $1225 \mathrm{MJ}$ eq per functional unit are achieved in scenario $\mathrm{D}$ and $\mathrm{F}$ respectively. These good results are related with energy requirements in the production of natural gas used in the generation of fossil-based heat and electricity.

\section{Conclusions}

This study highlights the opportunities and drawbacks of the production of biogas in an Italian biogas plant performing the codigestion of pig slurry and two energy crops (maize silage and triticale silage). Moreover, the consequent electricity and heat production from the biogas was also taken into consideration.

LCA methodology proved to be a valuable tool to assess the environmental performance of this biogas scenario. Real input and output flows for the whole system were identified and managed in detail from a cradle-to-gate perspective.

This study reported that the anaerobic co-digestion of pig slurry with energy crops allowed achieving environmental benefits specifically in terms of GHG emissions due to credits achieved through $\mathrm{CO}_{2}$ uptake during crops growth as well as the valorization of an organic waste into bioenergy. Uncontrolled emissions derived from digestate storage and application (such as ammonia and methane) showed to be an important source of environmental impacts, especially in terms of AP, EP and POFP. Concerning the bioenergy production plant, the production of electricity requirements showed up as an important contributor in ADP, ODP and CED, mainly due to the high ratio of non-renewable sources in the Italian electric profile. In addition, combustion emissions derived from the biogas combustion in the gas engine were found important in terms of GWP.

The consideration of the digestate as a valuable co-product in organic fertilization should involve also environmental benefits. Energy related categories such as ADP, CED and ODP should be considerably affected due to the avoidance of mineral fertilizers production. However, the environmental importance of digestate application in arable land became clear for other impact categories such as AP and EP due to ammonia and nitrate emissions. Northern Italy has designated several Nitrates Vulnerable Zones (70\% of the total area). Although this study falls into the restrictions for these areas, different digestate management alternatives should be considered in future studies in order to find out the most suitable digestate disposal option.

Improvement efforts should be focused on the reduction of uncontrolled emissions (mainly methane) that occur along the system (storage and operation activities), by means of technological development and maintenance. In this way, not only environmental burdens could be reduced but also bioenergy yield may be increased.

\section{Acknowledgments}

This research was supported by the following projects: COMDIGEST (CTM2010-17196), LIVE-WASTE (LIFE $12 \mathrm{ENV/CY/000544),}$ ManureEcoMine (ENV.213.6.3-2) and BIOGESTECA (15083/RCC) Dr. Jacopo Bacenetti thanks Regione Lombardia which financed a Postdoctoral Research Fellowship ("Progetto Dote Ricerca" financed by European Social Fund - Regione Lombardia).

\section{References}

[1] González-García S, García-Rey D, Hospido A. Environmental life cycle assessment for rapeseed-derived biodiesel. Int J Life Cycle Assess 2013;18: $61-76$.

[2] De Vries JW, Vinken TMWJ, Hamelin L, De Boer IJM. Comparing environmental consequences of anaerobic mono- and co-digestion of pig manure to produce bio-energy - a life cycle perspective. Bioresour Technol 2012;125: 239-48.

[3] Amiri S, Henning D, Karlsson BG. Simulation and introduction of a CHP plant in a Swedish biogas system. Renew Energy 2013;49:242-9.

[4] Capponi S, Fazio S, Barbanti L. $\mathrm{CO}_{2}$ savings affect the break-even distance of feedstock supply and digestate placement in biogas production. Renew Energy $2013 ; 37: 45-52$.

[5] European Renewable Energy Council, Renewable Energy Technology Roadmap $-20 \%$ by $2020 ; 2008$.

[6] Gerbens-Leenes PW, Hoekstra AY, van der Meer Th. The water footprint of energy from biomass: a quantitative assessment and consequences of an increasing share of bio-energy in energy supply. Ecol Econ 2009;68:1052-60.

[7] Benoist A, Dron D, Zoughaib A. Origins of the debate on the life-cycle greenhouse gas emissions and energy consumption of first-generation biofuels - a sensitivity analysis approach. Biomass Bioenergy 2012;40:133-42.

[8] Commission of the European Communities, An energy policy for Europe, Brussels; 2007.

[9] Holm-Nielsen JB, Al Seadi T, Oleskowicz-Popiel P. The future of anaerobic digestion and biogas utilization. Bioresour Technol 2009;100:5478-84.

[10] Igliński B, Buczkowski R, Iglińska A, Cichosz M, Piechota G, Kujawski W. Agricultural biogas plants in Poland: investment process, economical and environmental aspects, biogas potential. Renew Sustain Energy Rev 2012;16: 4890-900.

[11] Ferreira M, Marques IP, Malico I. Biogas in Portugal: status and public policies in a European context. Energy Policy 2012;43:267-74.

[12] Akbulut A. Techno-economic analysis of electricity and heat generation from farm-scale biogás plant: Çiçekdaği case study. Energy 2012;44:381-90.

[13] Dinuccio E, Balsari P, Gioelli F, Menardo S. Evaluation of the biogas productivity potential of some Italian agro-industrial biomasses. Bioresour Technol 2010;101:3780-3.

[14] Bacenetti J, Negri M, Fiala M, González-García S. Anaerobic digestion of different feedstocks: impact on energetic and environmental balances of biogas process. Sci Total Environ 2013;463-464:541-50.

[15] European Renewable Energy Council, Renewable energy policy review - Italy; 2009 .

[16] Eurostat http://epp.eurostat.ec.europa.eu [accessed 30.05.13].

[17] Hartmann JK. Life-cycle-assessment of industrial scale biogas plants. Germany: University of Goettingen; 2006.

[18] Abubaker J, Risberg K, Pell M. Biogas residues as fertilizers - effects on wheat growth and soil microbial activities. Appl Energy 2012;99:126-34.

[19] Börjesson P, Berglund M. Environmental systems analysis of biogas systems Part II: the environmental impact of replacing various reference systems. Biomass Bioenergy 2007;31:326-44.

[20] Poeschl M, Ward S, Owende P. Environmental impacts of biogas deployment - Part I: life cycle inventory for evaluation of production process emissions to air. J Clean Prod 2012;24:168-83.

[21] Campos-Pozuelo AE. Optimización de la digestión anaerobia de purines de cerdo mediante codigestión con residuos orgánicos de la industria agroalimentaria. Spain: Universitat de Lleida; 2001.

[22] ISO 14040. Environmental management - life cycle assessment - principles and framework; 2006.

[23] Börjesson P, Berglund M. Environmental systems analysis of biogas systems Part I: fuel-cycle emissions. Biomass Bioenergy 2006;30:469-85.

24] De Vries JW, Groenestein CM, De Boer IJM. Environmental consequences of processing manure to produce mineral fertilizer and bio-energy. J Environ Manag 2012;102:173-83.

[25] Poeschl M, Ward S, Owende P. Environmental impacts of biogas deployment - Part II: life cycle assessment of multiple production and utilization pathways. J Clean Prod 2012;24:184-201.

[26] Fabbri C, Soldano M, Piccinini S. L'agricoltore crede nel biogas e i numeri lo confermano; 2010.

[27] González-García S, Bacenetti J, Negri M, Fiala M, Arroja L. Comparative environmental performance of three different annual energy crops for biogas production in northern Italy. J Clean Prod 2013;43:71-83. 
[28] Gioelli F, Dinuccio E, Balsari P. Residual biogas potential from the storage tanks of non-separate digestate and digested liquid fraction. Bioresour Technol 2011;102:10248-51.

[29] ISO 14044. Environmental management - life cycle assessment - requirements and guidelines; 2006.

[30] Hansen TL, Sommer SG, Gabriel S, Christensen TH. Methane production during storage of anaerobically digested municipal organic waste. J Environ Qual 2006;35:830-6.

[31] Brentrup F, Küsters J, Lammel J, Kuhlmann $\mathrm{H}$. Methods to estimate on-field nitrogen emissions from crop production as an input to LCA studies in the agricultural sector. Int J Life Cycle Assess 2000;5:349-57.

[32] Weiland P. Biomass digestion in agriculture: a successul pathway for the energy production and waste treatment in Germany. Engineering in Life Sciences 2006;6:302-9.

[33] Weiland P. Production and energetic use of biogas from energy crops and wastes in Germany. Appl Biochem Biotechnol 2003;109:263-74.

[34] Rossier D. Adaptation de la method ecobilan pour la gestión environmentale de l'exploitation agricole. Lausanne, Switzerland: Service Romand de Vulgarisaation Agricole; 1998. p. 49.

[35] Nemecek T, Käggi T. Life cycle inventories of agricultural production systems. Final report ecoinvent v2.0 No. 15a. Zurich and Dübendorf, Switzerland: Agroscope FAL Reckenholz and FAT Taenikon, Swiss Centre for Life Cycle Inventories; 2007.

[36] Althaus HJ, Hischier R, Jungbluth N, Osses M, Primas A. Life cycle inventories of chemicals. Ecoinvent report No. 8, v2.0 EMPA. Dübendorf, Switzerland: Swiss Centre for Life Cycle Inventories; 2007.

[37] Spiermann M, Bauer C, Dones R. Transport services. Ecoinvent report No. 14 Dübendorf, Switzerland: Swiss Centre for Life Cycle Inventories; 2007.

[38] Dones R, Bauer C, Bolliger R, Burger B, Faist Enmenegger M, Frischknecht R, et al. Life cycle inventories of energy systems: results for current systems in
Switzerland and other UCTE countries. Ecoinvent report N. 5. Dübendorf: Paul Scherrer Institut Villigen, Swiss Centre for Life Cycle Inventories; 2007.

[39] Jungbluth N, Chudacoff M, Dauriat A, Dinkel F, Doka G, FAist Emmenegger M, et al. Life cycle inventories of bioenergy. Ecoinvent report No. 17. Dübendorf: Swiss Centre for Life Cycle Inventories; 2007.

[40] Guinée JB, Gorrée M, Heijungs R, Huppes G, Kleijn R, de Koning A, et al. Life cycle assessment. An operational guide to the ISO standards. Leiden: Centre of Environmental Science; 2001.

[41] Hischier R, Weidema B, Althaus HJ, Bauer C, Doka G, Dones R. Implementation of life cycle impact assessment methods. Ecoinvent report No. 3, v2.1. Dübendorf: Swiss Centre for Life Cycle Inventories; 2009.

[42] Cavinato C, Fatone F, Bolzonella D, Pavan P. Thermophilic anaerobic codigestion of cattle manure with agro-wastes and energy crops: comparison of pilot and full scale experiences. Bioresour Technol 2010;101:54550 .

[43] Dressler D, Loewen A. Nelles M. Life cycle assessment of the supply and use of bioenergy: impact of regional factors on biogas production. Int I Life Cycle Assess 2012;17:1104-15.

[44] Ministry for Environment, Land and Sea; Ministry for Agriculture, Food and Forestry Policies: Regions of Piedmont, Lombardy, Veneto, Emilia-Romagna and Friuli Venezia Giulia. Request from Italy for a derogation under paragraph 2(b) of Annex III to Directive 91/676/EEC from the limit of 170 kilograms of Nitrogen per hectare per year from livestock manure; 2010.

[45] Council Directive of 12 December 1991 concerning the protection of waters against pollution caused by nitrates from agricultural sources (91/676/EEC).

[46] Eurostat. Nitrogen balance in agriculture http://epp.eurostat.ec.europa.eu/ statistics_explained/index.php/Nitrogen_balance_in_agriculture; 2013 (accessed January 2014).

[47] Flesch TK, Desjardins RL, Worth D. Fugitive methane emissions from an agricultural biodigester. Biomass Bioenergy 2011;35:3927-35. 